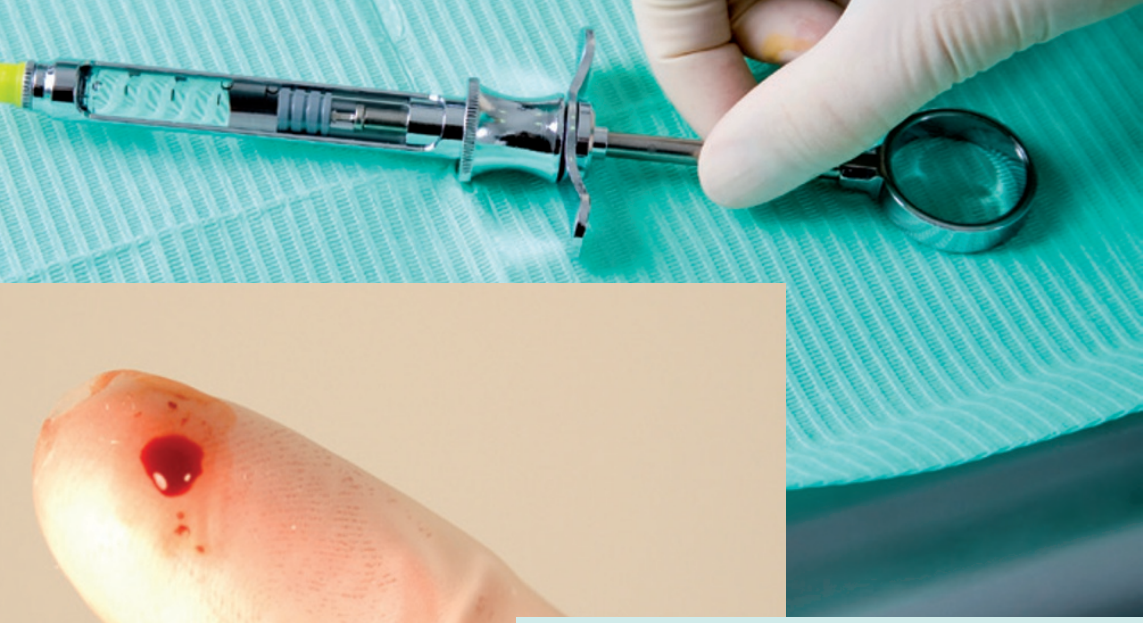

\title{
SURVEY SAYS DENTAL NURSES ARE AT HIGH RISK OF SHARPS INJURY
}

Just over half of dental nurses in the UK and the Republic of Ireland have had a needlestick injury at some stage in their career.

This is a finding of a survey conducted by the British Association of Dental Nurses (BADN) in conjunction with Initial Medical, healthcare waste management experts. The survey was conducted online between June-August 2014 and received 1,216 responses.

Of those who said they'd received a needlestick injury, $60 \%$ said they'd received more than one, with $11 \%$ saying they'd been injured in the past year. In terms of when their injury occurred, $41 \%$ of respondents who had had a sharps injury said their last injury had happened after use, before disposal.

Encouragingly, $97.4 \%$ of those whod received an injury knew what steps to take. Out of all survey respondents, $52 \%$ rated their needlestick injury training as very good, with $29 \%$ rating it good. Interestingly, $21 \%$ of UK respondents said that since the Health \& Safety (Safe Instruments in Healthcare) Regulations 2013 came into force, their practice had not put in place new safety procedures or safety devices.

Of those who had had an injury, 1.24\% said they'd acquired a blood-borne virus as a result.

Rebecca Allen, category manager for Initial Medical, said: 'The risk of infection following a needlestick injury is estimated to be one in three for HBV, one in 30 for $\mathrm{HCV}$ and one in 300 for HIV for healthcare workers worldwide, so it is vital that best practice is followed. If you don't feel like you have had appropriate sharps safety training or you don't feel the right procedures are being followed, then it is imperative you make this known within your practice'

\section{Local Anaesthetic Update in Theory and Techniques}

Date: 4 November 2014, 9 am

Venue: Wrexham Medical Institute

Telephone: 01745534430

Email: sandomtf@cardiff.ac.uk www.walesdeanery.org/dental

\section{BSDHT Oral Health Conference}

Competence, confidence

and clarity

Date: 21-22 November 2014

Venue: ACC, Liverpool

http://www.bsdht.org.uk/OHC_214_ LANDING_PAGE.html

\section{Periodontology: Non-Surgical Periodontal Therapy}

Date: 28-29 November 2014

Venue: UCL Eastman Dental Institute http://www.badt.org.uk/events/ downloads/Periodontology(1).pdf

\section{Implant Maintenance with Charlotte Curran}

Date: 28 November 2014

Venue: Compass Building, Enderby, Leicester http://www.dental-education.co.uk/ locations/view/124

\section{SDCEP Guidelines on Periodontal Treatment: NHS Education for Scotland}

Date: 2 December 2014, 1 pm Venue: Centre for Health Science, Inverness

https://portal.scot.nhs.uk/ 